\title{
Rancang Bangun Prototipe Sensor Pintar Wearable Berbasis Internet of Things untuk Monitoring Popok
}

\author{
Budiman A. Wibowo, Hendra Kusuma, dan Tasripan \\ Departemen Teknik Elektro, Fakultas Teknologi Elektro, Institut Teknologi Sepuluh Nopember (ITS) \\ e-mail: hendraks@ee.its.ac.id
}

\begin{abstract}
Abstrak-Popok adalah suatu jenis pakaian yang berfungsi untuk menampung urine dan feses orang yang tidak bisa mengendalikan pergerakan kandung kemih ataupun pergerakan ususnya. Apabila popok sudah berisi harus segera diganti agar tidak menimbulkan iritasi pada kulit. Akan tetapi, seringkali pengasuh lupa ataupun terlalu sibuk sehingga terlambat dalam mengganti popok. Maka dari itu, dikembangkan suatu sensor pintar yang dapat dikenakan (wearable) untuk menyelesaikan permasalahan tersebut. Sensor pintar ini berfungsi untuk mengawasi kondisi kelembapan dan temperatur popok dan dapat memberikan informasi tersebut secara realtime tanpa harus memeriksa popok secara rutin. Pada makalah ini akan dirancang suatu sensor pintar berbasis Internet of Things yang dapat dikenakan (wearable). Sistem ini terdiri dari sebuah sensor pintar menggunakan sensor HTU21 untuk mendeteksi kondisi kelembapan dan temperatur popok dan mengirimkan data tersebut ke aplikasi android melalui bluetooth dan sebuah aplikasi android untuk menampilkan hasil pembacaan dan juga memberikan notifikasi apabila popok sudah berisi. Apabila tingkat kelembapan popok sudah melewati $60 \%$ dan temperature sudah melewati $33^{\circ} \mathrm{C}$ maka aplikasi akan memberikan notifikasi dan membunyikan alarm sebagai pengingat untuk mengganti popok. Dari 25 kali pengujian menggunakan urine, perangkat berhasil mendeteksi keberadaan urine sebanyak 18 kali. Sehingga persentasi keberhasilannya adalah sebesar $72 \%$.
\end{abstract}

Kata Kunci-Bluetooth Low Energy, Diaper, Internet of Things, Smart Device, Wearable Sensors.

\section{PENDAHULUAN}

$\mathrm{P}$ OPOK adalah semacam pakaian yang berfungsi untuk menampung urin dan feses agar tidak mengotori lingkungan sekitar. Popok digunakan karena tidak semua manusia memiliki kemampuan untuk mengendalikan pergerakan kandung kemih atau pergerakan ususnya, baik hal itu dikarenakan oleh otak yang belum cukup berkembang untuk mengatur pergerakan kandung kemihnya seperti pada bayi ataupun dikarenakan oleh penyakit yang menyebabkan ketidakmampuan dalam mengendalikan pergerakan kandung kemih seperti kelumpuhan yang bisa dialami pada kasus-kasus orang dewasa. Popok yang berada di pasaran pada umumnya terbagi menjadi dua kategori berdasarkan penggunanya, yaitu popok untuk bayi dan popok untuk orang dewasa.

Popok yang basah ataupun kotor setelah diisi oleh urin dan feses apabila dibiarkan terlalu lama tanpa diganti dapat menyebabkan munculnya penyakit pada kulit seperti iritasi yang disebut juga sebagai ruam popok [1]. Ruam popok ini adalah masalah yang umum ditemui apabila sedang merawat bayi ataupun orang tua yang mengenakan popok. Biasanya ruam popok hanya menyebabkan iritasi ringan pada kulit, akan tetapi dalam beberapa kasus unik dapat pada infeksi bateri dan juga komplikasi yang dapat berujung kepada kematian. Ruam popok ini dapat diatasi dengan rutin mengganti popok, memberikan bedak anti-jamur, atau krim hydrocortisone [2].

Beberapa merek popok yang ada di pasaran sekarang ini sudah menggunakan bahan yang dapat mendeteksi urin dalam popok, dimana bahan ini akan berubah warna ketika terjadi kontak antara bahan tersebut dengan urin dalam jumlah tertentu. Perawat hanya perlu melihat popok untuk memastikan apakah kondisi popok sudah kotor atau tidak. Akan tetapi popok seperti ini juga masih kurang baik dikarenakan pada saat bahan pada popok mendeteksi keberadaan urin, perawat tidak akan langsung mengetahuinya sehingga kemungkinan terjadinya ruam popok akan tetap ada.

Untuk menjawab permasalahan tersebut, pada penelitian ini akan dibangun suatu sensor pintar yang dapat dikenakan pada popok yang mampu mengawasi dan memberitahu kondisi popok secara real-time kepada perawat dan juga memberikan peringatan apabila kondisi kelembapan dan temperature popok telah melewati batas tertentu.

\section{DASAR TEORI}

\section{A. Bluno Beetle}

Bluno Beetle adalah board microcontroller berbasis Arduino UNO terintegrasi modul BLE yang ditujukan untuk penggunaan perangkat wearable [3]. Microcontroller adalah sebuah komputer kecil dalam sebuah IC (integrated circuit), yang memiliki satu atau lebih CPU, memori, dan GPIO (general purpore input output) yang dapat diprogram. Bluno menggunakan bahasa pemrograman dan library yang didasari dari bahasa pemrograman $\mathrm{C}++$ dan perangkat lunak Arduino (IDE). Untuk memprogram Bluno Beetle dapat dilakukan dengan dua cara, yaitu dengan menggunakan kabel USB atau dengan cara nirkabel menggunakan Bluetooth Low Energy.
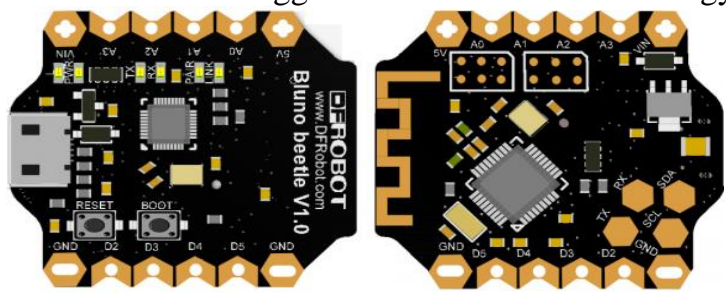

Gambar 1. Bluno Beetle [3]. 


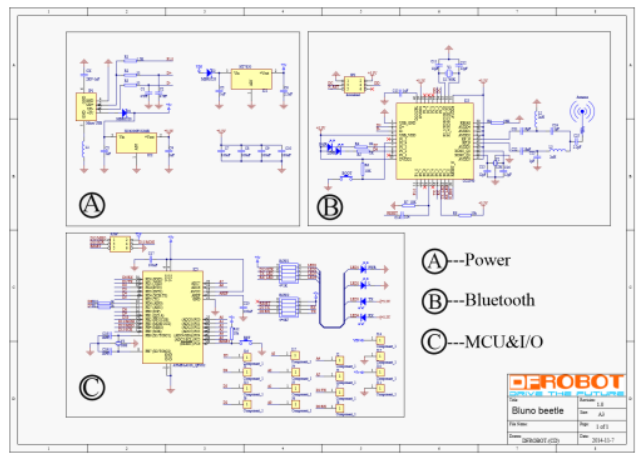

Gambar 2. Skematik Bluno Beetle [4].

Tabel 2.

Power interface bluno beetle [3].

\begin{tabular}{cc}
\hline \hline Silkscreen & Description \\
\hline VIN & external power supply $<8 \mathrm{~V}$ \\
$5 \mathrm{~V}$ & $5 \mathrm{~V}$ positive supply \\
GND & GND \\
\hline \hline
\end{tabular}

Tabel 1.

Diagram pinout bluno beetle [3].

\begin{tabular}{cccccc}
\hline \hline \multirow{2}{*}{ Silkscreen } & $\begin{array}{c}\text { Digital } \\
\text { Pin }\end{array}$ & $\begin{array}{c}\text { PWM } \\
\text { Channel }\end{array}$ & $\begin{array}{c}\text { Analog } \\
\text { Channel }\end{array}$ & UART & I2C \\
\hline RX & 0 & & & Serial1 & \\
TX & 1 & & & & SDA \\
SDA & A4 & & & SCL \\
SCL & A5 & & & \\
D2 & 2 & & & \\
D3 & 3 & 3 & & \\
D4 & 4 & & & \\
D5 & 5 & 5 & A0 & \\
A0 & A0 & & A1 & \\
A1 & A1 & & A2 & \\
A2 & A2 & & A3 & \\
A3 & A3 & & & \\
\hline
\end{tabular}

Tabel 3.

Spesifikasi bluno beetle [3].

\begin{tabular}{cc}
\hline \hline Bluetooth Chip & CC2540 \\
\hline Sensitivity & $(-93 \mathrm{dBm})$ \\
Working Temperature : & $\left(-10^{\circ} \mathrm{C} \sim+85^{\circ} \mathrm{C}\right)$ \\
Maximum Distance & $50 \mathrm{~m}($ Open field $)$ \\
Microcontroller: & ATmega328P \\
Clock frequency: & $16 \mathrm{MHz}$ \\
Working voltage: & $5 \mathrm{~V} \mathrm{DC}$ \\
Digital Pin & $\mathrm{x} 4$ \\
Analog Pin & $\mathrm{x} 4$ \\
PWM Output & $\mathrm{x} 2$ \\
UART interface & $\mathrm{x} 1$ \\
I2C interface & $\mathrm{x} 1$ \\
Micro USB interface & $\mathrm{x} 1$ \\
Power port & $\mathrm{x} 2$ \\
\hline \hline
\end{tabular}

B. Sensor Suhu dan Temperatur HTU21

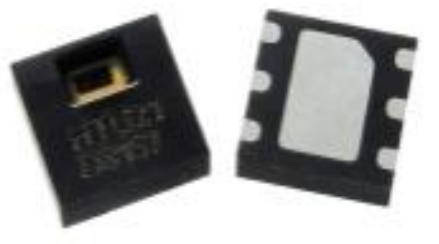

Gambar 3. Sensor HTU21 [5].
HTU21 merupakan sebuah sensor temperatur dan kelembapan. IC HTU21 ini sudah mencakup 4 buah pin hubungan yaitu Vcc, Ground, SDA, dan SCL. (Gambar 3)

Tabel 4.

Spesifikasi HTU21 [6].

\begin{tabular}{lccc}
\hline \hline Ratings & Symbol & Value & Unit \\
\hline Storage Temperature & Tstg & -40 to 125 & ${ }^{\circ} \mathrm{C}$ \\
Supply Voltage (Peak) & Vcc & $3.8 \mathrm{~V}$ & Vdc \\
Humidity Operating Range & $\mathrm{RH}$ & 0 to 100 & $\% \mathrm{RH}$ \\
Temperature Operating Range & $\mathrm{Ta}$ & -40 to +125 & ${ }^{\circ} \mathrm{C}$ \\
VDD to GND & & -0.3 to $3.6 \mathrm{~V}$ & $\mathrm{~V}$ \\
Digital I/O pins (DATA/SCK) to & & -0.3 to VDD+0.3 & $\mathrm{V}$ \\
VDD & & & \\
Input current on any pin & & -10 to +10 & $\mathrm{~mA}$ \\
\hline
\end{tabular}

Tabel 5.

Karakteristik kelistrikan HTU21 [6].

\begin{tabular}{lllllll}
\hline Characteristics & & Symbol & Min & Typ & Max & Unit \\
\hline Voltage Supply & & VDD & 1.5 & 3.0 & 3.6 & $\mathrm{~V}$ \\
Current & Sleep Mode & idd & & 0.02 & 0.14 & $\mu \mathrm{A}$ \\
consumption & Measuring & & 300 & 450 & 500 & $\mu \mathrm{A}$ \\
Power & Sleep mode & & & 0.06 & 0.5 & $\mu \mathrm{W}$ \\
Dissipation & Average & & & 2.7 & & $\mu \mathrm{W}$ \\
& 8bit & \multicolumn{5}{c}{} \\
Communication & & digital 2-wire interface, $\mathrm{I}^{2} \mathrm{C}$ protocol \\
Heater & $\mathrm{VDD}=3 \mathrm{~V}$ & $5.5 \mathrm{~mW} / \Delta \mathrm{T}=+0.5-1.5^{\circ} \mathrm{C}$ \\
Storage & & $-40^{\circ} \mathrm{C} / 125^{\circ} \mathrm{C}$ & & \\
\hline
\end{tabular}

\section{Internet of Things}

Internet of Things atau yang biasa disingkat dengan IoT merupakan sebuah konsep sistem jaringan fisik yang terdiri dari komponen elektronik, perangkat lunak, sensor, actuator dan terhubung dalam suatu jaringan internet, sehingga objek tersebut dapat saling bertukar data [7].

IoT melibatkan konektivitas dari perangkat seperti Smartphone, Tablet, dan laptop, kepada perangkat-perangkat ataupun objek sehari-hari yang biasanya tidak dapat terhubung ke internet. Sehingga dengan ditambahnya teknologi IoT ini, perangkat-perangkat ini dapat berkomunikasi dan berinteraksi melalui internet.

Skema dari hubungan antar komponen dapat dilihat pada Gambar 4 dimana aplikasi penggunaan IoT mencakup hampir seluruh aspek kehidupan manusia. Dengan adanya konsep IoT ini, aspek-aspek tersebut dapat dikontrol oleh suatu alat pengendali yang terhubung dengan internet, yang kemudian juga dapat terhubung satu sama lain, sehingga menciptakan adanya integrase untuk meningkatkan efisiensi, akurasi, dan faktor ekonomi.

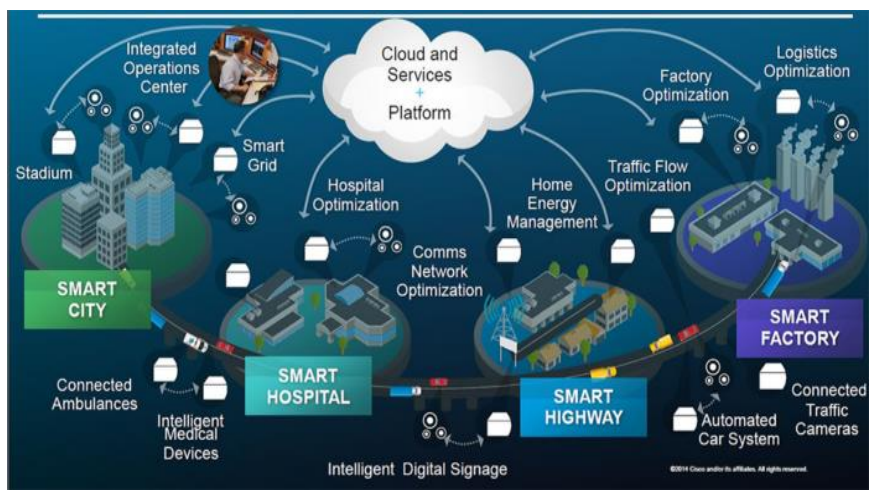

Gambar 4. Aplikasi dari IoT [8]. 


\section{Moving Average}

Moving Average adalah perhitungan untuk menganalisa data dengan cara menciptakan sekumpulan rata-rata dari subset yang berbeda dari keseluruhan data. Moving Average disebut juga sebagai Moving Mean atau Rolling Mean [9] dan juga merupakan sebuah filter finite impulse response.

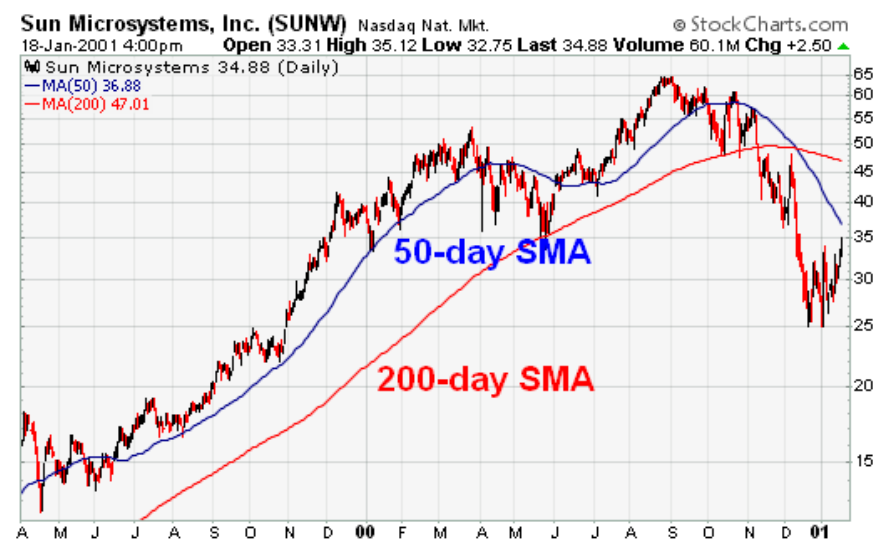

Gambar 5. Moving Average [10].

Moving Average biasanya digunakan pada data yang berjalan seiring waktu untuk menghaluskan fluktuasi jangka pendek. Batas antara jangka pendek dan jangka panjang bergantung pada aplikasi dan parameter dari Moving Average dapat diatur sedemikian rupa.

\section{PERANCANGAN SISTEM}

\section{A. Diagram Blok Sistem}

Diagram blok sistem Sensor Pintar wearable berbasis Internet of Things secara keseluruhan ditunjukkan pada Gambar 6.

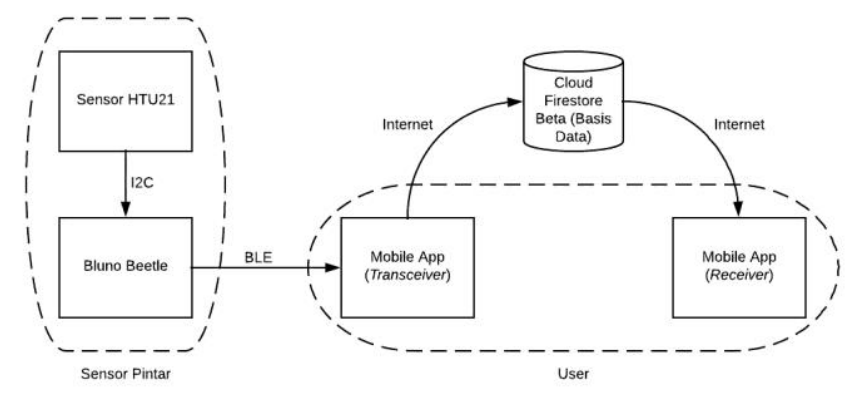

Gambar 6. Diagram blok sistem.

Pada penelitian ini, digunakan Bluno Beetle sebagai tempat mengolah hasil pembacaan sensor, sedangkan Mobile App pada sistem digunakan sebagai tempat menunjukkan hasil pembacaan sensor dan juga mengirimkan data dari database ataupun mengambil data dari database, dan juga memberikan peringatan kepada user apabila kondisi kelembapan dan temperatur popok melewati batas tertentu.

\section{B. Perancangan Perangkat Keras}

Perangkat keras pada penelitian ini meliputi Smart Sensor dan bodi luar sistem.

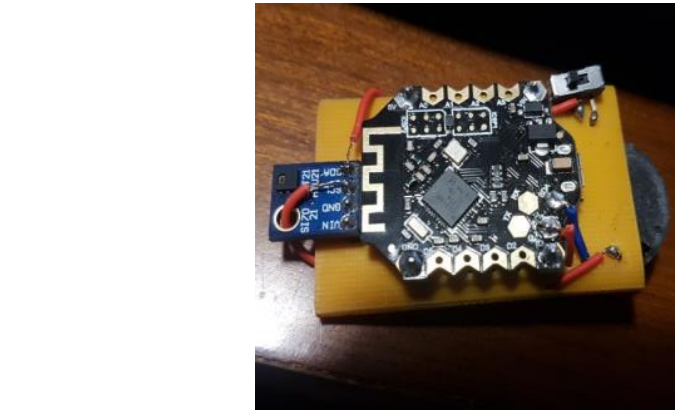

Gambar 7. Sensor pintar.

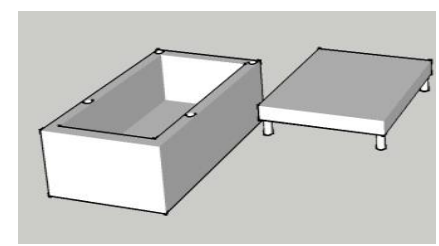

Gambar 8. Packaging sensor pintar.

Smart Sensor dimaksudkan sebagai komponen sistem yang bertugas untuk mendeteksi tingkat kelembapan dan temperatur popok secara realtime, melakukan penghalusan pembacaan dengan moving average, mengkonversikan hasil pembacaan menjadi biner, mengirimkan data ke mobile app. Smart Sensor ini terdiri dari sensor temperatur dan kelembapan HTU21, microcontroller Bluno Beetle, dan satu buah baterai kancing LIR2032 3.6v.

Untuk mencegah gangguan dalam proses pembacaan temperatur dan kelembapan pada sistem dalam penelitian ini, maka pengambilan data harus terhindar dari udara luar yang dapat menganggu. Maka dari itu dibutuhkan suatu bodi luar yang mampu mengurangi udara luar agar tidak mengganggu kinerja sistem. Selain itu, bodi luar juga menjadi tempat penempatan seluruh komponen dalam sistem. Bodi luar pada penelitian ini dibuat menggunakan teknik 3D Printing. Pada tampak atas bodi luar sistem terdapat lubang-lubang kecil yang berada tepat di atas sensor HTU21, hal ini memungkinkan agar udara bisa masuk dan mengenai sensor. Rancangan bodi luar sistem memiliki dimensi $6,5 \times 5,2 \times 3,3 \mathrm{~cm}$. Desain rancangan dari bodi luar sistem ditunjukkan pada Gambar 7 .

\section{Perancangan Perangkat Lunak}

Perangkat lunak yang diimplementasikan pada penelitian ini meliputi program pada Arduino IDE dan program pada mobile app yang terbagi menjadi dua yaitu transceiver dan receiver.

Pola kerja dari program utama sensor akan diilustrasikan oleh sebuah flowchart pada Gambar 9.

Program akusisi data temperature dan kelembapan dilakukan melalui perangkat lunak Arduino IDE. Akusisi dilakukan oleh sensor HTU21 yang dihubungkan ke Bluno Beetle. Pemrosesan data menggunakan moving average dilakukan untuk memperhalus data dari spike yang bisa terjadi. Setelah didapatkan data hasil pembacaan sensor yang sudah dihaluskan, data akan dikonversikan menjadi satu buah data dalam bentuk byte. Akan tetapi sebelum dikonversikan ke byte, data temperatur akan diolah lagi karena diinginkan data pembacaan temperatur ada satu angka di belakang koma. 


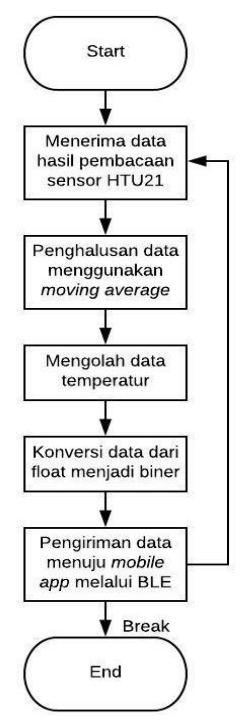

Gambar 9. Flowchart program utama sensor pintar.

Setelah temperatur diolah, barulah data temperatur dan kelembapan diubah menjadi byte. Setelah data dikonversi menjadi data sebesar 16 bit. Data dapat langsung dikirim ke mobile app dengan cara komunikasi serial. Data akan dikirimkan sekali setiap 500ms.

Pola kerja program mobile app transceiver secara keseluruhan akan digambarkan pada flowchart yang ditunjukkan pada Gambar 10.

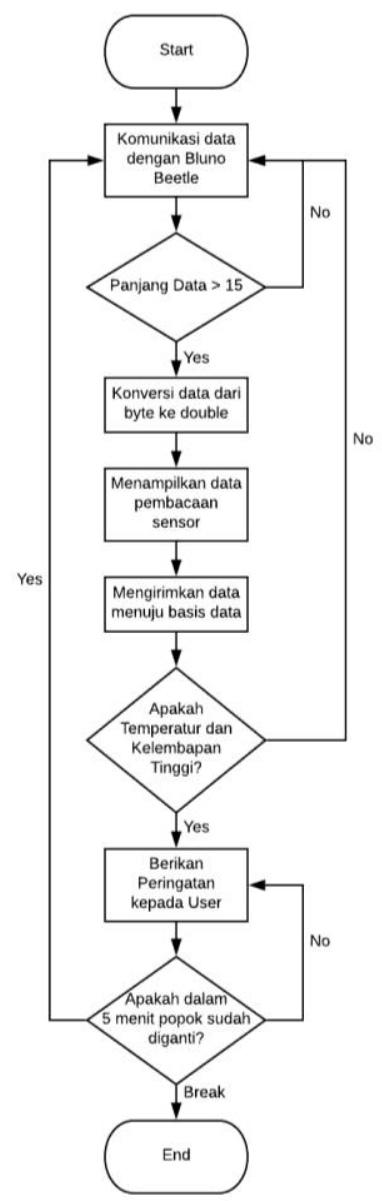

Gambar 10. Flowchart program utama mobile app transceiver.

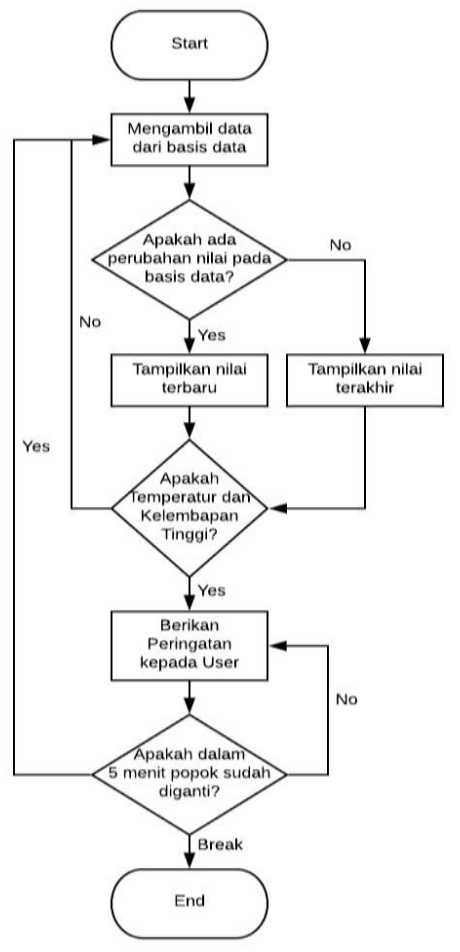

Gambar 11. Flowchart program utama mobile app receiver.

Pertama-tama yang akan diperiksa adalah jumlah panjang data yang diterima oleh mobile app. Apabila panjang data yang diterima lebih besar dari 15 berarti data berhasil terkirim tanpa adanya error dan program akan melanjutkan ke proses selanjutnya. Akan tetapi apabila panjang data yang diterima lebih sedikit atau sama dengan 15 , berarti ada data yang hilang saat pengiriman dan aplikasi tidak akan melanjutkan ke proses selanjutnya, melainkan akan mengulang terus selama ada data serial yang diterima oleh mobile app. Apabila data sudah diterima oleh mobile app langkah selanjutnya adalah dengan mengubah kembali data yang berbentuk byte menjadi double. Setelah data dikonversi menjadi double, data temperatur diolah ke bentuk aslinya. Setelah data temperatur diolah, barulah data hasil konversi tadi bisa ditampilkan. Setelah data ditampilkan, proses selanjutnya pada mobile app adalah mengirimkan data hasil pembacaan sensor menuju database melalui internet. Selagi semua proses yang sudah disebutkan berjalan terus, apabila mobile app mendeteksi tingkat kelembapan dan temperature yang tinggi maka mobile app akan berbunyi dan menampilkan notifikasi sebagai bentuk pengingat kepada user.

Pola kerja program mobile app receiver secara keseluruhan akan digambarkan pada flowchart yang ditunjukkan pada Gambar 11.

Pertama-tama mobile app membaca data-data yang tersimpan di database apabila tidak ada perubahan nilai pada database maka akan ditampilkan nilai yang terakhir diambil, akan tetapi apabila dideteksi ada perubahan pada nilai-nilai tersebut, maka yang akan ditampilkan adalah nilai-nilai yang paling baru. Setelah mobile app mengambil data dari Cloud Firestore, proses selanjutnya adalah untuk menampilkan data yang telah diambil tersebut. Setelah data diambil dan ditampilkan, sama seperti pada mobile app transceiver, 
dilakukan pengecekan apakah temperatur dan kelembapan sudah mencapai nilai yang tinggi (dalam kasus ini temperatur $=30$ dan kelembapan $=60 \%$ ). Apabila sudah melebihi nilai tersebut, aplikasi akan berbunyi dan memberikan notifikasi sebagai bentuk pengingat kepada user.

\section{PENGUJIAN DAN ANALISIS SISTEM}

\section{A. Pengujian Sensor HTU21}

Sensor HTU21 digunakan dalam deteksi tingkat kelembapan dan temperatur. Pengujian sensor HTU21 perlu dilakukan untuk mengetahui apakah pembacaan sensor HTU21 sesuai dengan kebutuhan atau tidak. Pengujian dilakukan dengan cara mengukur output HTU21 yang terukur pada berbagai kondisi. Pengukuran besaran dilakukan dengan mengamati serial monitor Arduino IDE yang menampilkan output sensor dengan baud rate 115200 bps selama 8 menit dan 20 detik. Hasil pengujian sensor HTU21 dapat dilihat pada Tabel 6.

Tabel 6.

Hasil pembacaan terakhir sensor HTU21

\begin{tabular}{clcc}
\multicolumn{4}{c}{ Hasil pembacaan terakhir sensor HTU21 } \\
\hline \hline No. & \multicolumn{1}{c}{ Kondisi } & Suhu $\left({ }^{\circ} \mathrm{c}\right)$ & $\begin{array}{c}\text { Kelembapan } \\
(\%)\end{array}$ \\
\hline 1. & Ruangan dengan AC & 26,2 & 40 \\
2. & Ruangan tanpa AC & 30,8 & 48 \\
3. & Kamar Mandi & 29.1 & 62 \\
\hline \hline
\end{tabular}

Dari hasil pembacaan dapat disimpulkan bahwa output sudah sesuai seperti dengan yang diinginkan, yaitu perubahan pembacaan suhu dari ruangan tanpa $\mathrm{AC}$ dengan ruangan dengan $\mathrm{AC}$, dan juga perubahan tingkat kelembapan pada ruangan biasa dengan kamar mandi.

\section{B. Pengujian Subsistem Sensor Pintar}

Pada tahap pengujian subsistem sensor pintar ini akan dilakukan pengujian pada subsistem sensor pintar, dimana akan dilakukan pengamatan terhadap hasil pembacaan sensor pintar pada berbagai kondisi. Kondisi pengujian adalah kamar dengan AC, kamar tanpa AC, dan kamar mandi. Pengujian dilakukan selama 8 menit dan 20 detik. Hasil pembacaan sensor dapat dilihat pada Tabel 7 .

Tabel 7.

Hasil pembacaan sensor pintar

\begin{tabular}{llcc}
\hline \hline No. & Kondisi & Suhu $\left({ }^{\circ} \mathrm{c}\right)$ & Kelembapan $(\%)$ \\
\hline 1. & Ruangan tanpa AC & 27,6 & 45 \\
2. & Ruangan dengan AC & 24,4 & 39 \\
3. & Kamar Mandi & 30.3 & 51 \\
\hline \hline
\end{tabular}

Dari hasil pembacaan dapat ditarik kesimpulan bahwa packaging tidak mempengaruhi hasil pembacaan kelembapan dan temperatur.

\section{Pengujian Komunikasi antar Subsistem}

Pada pengujian komunikasi antar sistem akan dilakukan pengamatan data yang ditampilkan pada tiap subsistem dan perbandingan hasil data yang ditampilkan pada transceiver, database, dan receiver pada satu waktu. Hasil perbandingan data yang ditampilkan antara transceiver, database, dan receiver dapat dilihat pada Gambar 12.

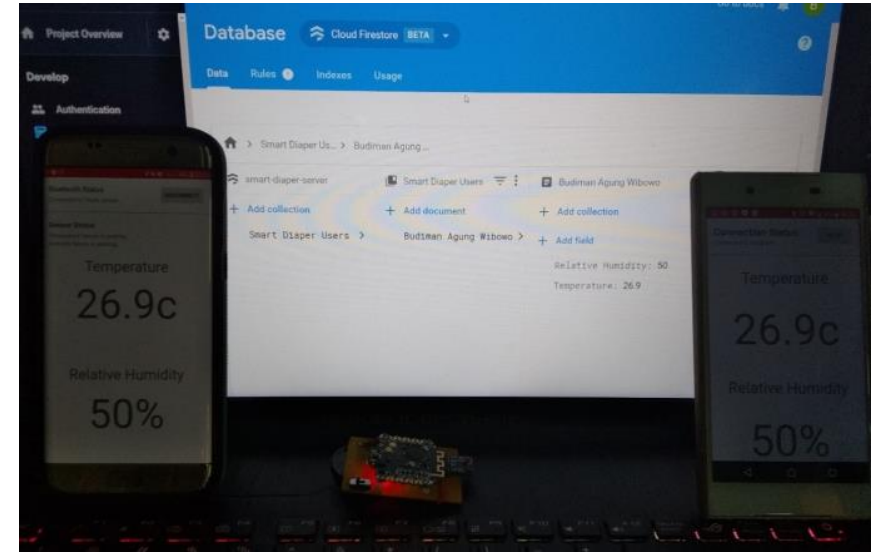

Gambar 12. Pengamatan data yang ditampilkan pada transceiver, database, dan receiver.

Berdasarkan hasil pengamatan penulis, data yang ditampilkan antara aplikasi transceiver, basis data, aplikasi receiver adalah sama. Akan tetapi selama pengamatan, terjadi delay komunikasi data sedikit.

\section{Pengambilan Data pada Popok}

Pada tahap ini dilakukan pengambilan data secara langsung pada popok yang digunakan. Pengambilan data dilakukan dengan cara menempelkan smart sensor kepada popok. Tujuan pengambilan data adalah untuk menentukan batas bawah kondisi kotor popok dan juga untuk melihat pengaruh kondisi luar terhadap pembacaan. Pengujian pertama adalah pada popok dewasa yang kering, dimana pengukuran akan dilakukan pada ruangan tanpa $\mathrm{AC}$, ruangan dengan $\mathrm{AC}$, dan kamar mandi. Hasil pembacaan pada popok dewasa dengan berbagai kondisi ditunjukkan pada Tabel 8.

Tabel 8.

Pengukuran pada popok dewasa

\begin{tabular}{clcc}
\hline \hline No. & Kondisi & Suhu $\left({ }^{\circ} \mathrm{c}\right)$ & Kelembapan $(\%)$ \\
\hline 1. & Kamar Mandi & 32,6 & 53 \\
2. & Ruangan tanpa AC & 33,5 & 48 \\
3. & Ruangan dengan AC & 33,0 & 49 \\
\hline \hline
\end{tabular}

Dari Tabel 8 dapat dilihat bahwa tidak terjadi perubahan tingkat kelembapan dan temperatur yang signifikan. Sehingga dapat ditarik kesimpulan bahwa tingkat kelembapan dan temperatur di dalam celana berbeda dengan tingkat kelembapan dan temperatur udara luar.

Pengukuran yang kedua dilakukan pada popok bayi, sampel yang digunakan ada 3 orang anak. Dimana dilakukan pemasangan smart sensor pada popok bayi selama 8 menit. Hasil pembacaan sensor pada popok bayi ditunjukkan pada Tabel 9.

Tabel 9.

Pengukuran pada popok bayi

\begin{tabular}{ccccc}
\hline \hline Subjek & $\begin{array}{c}\text { Kondisi } \\
\text { Popok }\end{array}$ & $\begin{array}{c}\text { Suhu } \\
\left({ }^{\circ} \mathrm{c}\right)\end{array}$ & $\begin{array}{c}\text { Kelembapan } \\
(\%)\end{array}$ & $\begin{array}{c}\text { Kondisi } \\
\text { Pengukuran }\end{array}$ \\
\hline Aisyah & Kotor & 33,8 & 67 & Berlari \\
(1 Tahun) & Bersih & 33,7 & 56 & Berlari \\
Riskina & Kotor & 33.7 & 61 & Tertidur \\
(2 Tahun) & Bersih & 35,8 & 53 & Tertidur \\
Syahrul & Kotor & 33,5 & 66 & Tertidur \\
(8 Bulan) & Bersih & 33,3 & 54 & Tertidur \\
\hline \hline
\end{tabular}


Dari Tabel 9, penulis mengambil nilai-nilai terendah sebagai parameter penentuan kondisi popok mulai kotor. Sehingga nilai-nilai yang diambil sebagai parameter adalah sebagai berikut:

Temperatur $=33,0 ;$ dan Kelembapan $=60 \%$

\section{E. Pengujian Sistem Sensor Pintar Wearable berbasis Internet of Things}

Setelah didapat batas bawah dari pengujian sebelumnya, batas bawah diimplementasikan ke dalam program aplikasi android. Pengujian keseluruhan sistem dilakukan dengan cara memasang smart sensor pada popok kemudian diberikan cairan dan membuktikan apakah aplikasi android akan memberikan notifikasi. Pengujian dilakukan menggunakan 1 merek popok dewasa dan 4 merek popok bayi. Hasil pengujian sistem sensor pintar dapat dilihat pada Tabel 10.

Tabel 10.

Pengujian sistem sensor pintar berbasis IoT

\begin{tabular}{llll}
\hline \hline Jenis Popok & $\begin{array}{l}\text { Jumlah } \\
\text { Pengujian }\end{array}$ & $\begin{array}{l}\text { Jumlah } \\
\text { Keberhasilan }\end{array}$ & $\begin{array}{l}\text { Persentase } \\
\text { Keberhasilan }\end{array}$ \\
\hline $\begin{array}{l}\text { Indomaret(Popok } \\
\text { Dewasa) }\end{array}$ & 5 & 4 & $80 \%$ \\
Sweety(Popok Bayi) & 5 & 4 & \\
Popoku(Popok Bayi) & 5 & 3 & $80 \%$ \\
Merries(Popok Bayi) & 5 & 3 & $60 \%$ \\
Mamypoko(Popok & 5 & 4 & $60 \%$ \\
Bayi) & & & $80 \%$ \\
Total & 25 & 18 & $72 \%$ \\
\hline \hline
\end{tabular}

\section{KESIMPULAN/RINGKASAN}

Berdasarkan percobaan yang telah dilakukan pada penelitian ini didapat beberapa kesimpulan. Berdasarkan pengamatan, sensor pintar memberikan sedikit rasa tidak nyaman apabila diletakkan di bawah popok, dan tidak memberikan rasa tidak nyaman apabila diletakkan di bagian depan ataupun belakang. Tingkat kelembapan dan temperatur di dalam celana berbeda dengan tingkat kelembapan dan temperatur udara luar sehingga sensor pintar tepat digunakan pada kondisi tersebut. Sistem sensor pintar wearable berbasis Internet of Things yang dirancang mampu memberikan pengingat ketika kelembapan dan temperatur melewati batas tertentu dengan tingkat keberhasilan sebesar $72 \%$

\section{DAFTAR PUSTAKA}

[1] H. T. Shin, "Diagnosis and Management of Diaper Dermatitis," Pediatr. Clin. North Am., vol. 61, no. 2, pp. 367-382, 2014.

[2] J. Mersch, "Diaper Rash," www.medicinenet.com, 2018. .

[3] DFRobot, "DFRobot," www.dfrobot.com, 2018. [Online]. Available: https://www.dfrobot.com/wiki/index.php/Bluno_Beetle_SKU:DFR0 339.

[4] RobotShop, "RobotShop," www.robotshop.com, 2018. [Online]. Available: https://www.robotshop.com/media/files/pdf/DFR0339Bluno-beetle-V1.0.pdf.

[5] TE Connectivity, "HTU21D RH/T SENSOR," www.te.com, 2018. [Online]. Available: https://www.te.com/usa-en/productHPP845E031.html.

[6] TE Connectivity, "Datasheet HTU21D RH/T SENSOR," www.te.com/, 2018. [Online]. Available: https://www.te.com/commerce/DocumentDelivery/DDEController?A ction=showdoc\&DocId=Data+Sheet\%7FHPC199_6\%7FA6\%7Fpdf \%7FEnglish\%7FENG_DS_HPC199_6_A6.pdf\%7FHPP845E031.

[7] R. Zafalon, "Smart System Design: Industrial Challenges and Perspectives," in IEEE 14th International Conference on Mobile Data Management, 2013, p. 3.

[8] A. Banafa, "Datafloq," datafloq.com, 2018. [Online]. Available: https://datafloq.com/read/internet-of-things-more-than-smartthings $/ 1060$.

[9] E. Booth, J. Mount, and J. H. Viers, "Hydrologic Variability of the Cosumnes River Floodplain," Hydrol. Var. Cosumnes River Floodplain, vol. 4, no. 2, 2016.

[10] Anonymous, "Moving Averages," cns.bu.edu, 2018. [Online]. Available: indicators/Moving Averages.htm. 